\title{
Synergistic Integration of Detailed Meteorological and Community Information for Evacuation from Weather-Related Disasters: Proposal of a "Disaster Response Switch"
}

\author{
Kensuke Takenouchi $^{1} \cdot$ Katsuya Yamori $^{1}$
}

Accepted: 17 October 2020/Published online: 30 November 2020

(C) The Author(s) 2020

\begin{abstract}
Meteorological information used for disaster prevention has developed rapidly in terms of both type and specificity. The latest forecasting models can predict weather with very high resolutions that can characterize disaster risk at the local level. However, this development can lead to an overdependency on the information and a wait-and-see attitude by the public. At the same time, residents share and use various types of information for disaster response, such as local conditions, in addition to official disaster information. Our research in Japan verified the practicality and efficiency of synergistically integrating these types of information by examining actual evacuation cases. The current numerical forecasting models sufficiently identify locality from the viewpoint of various administrative scales such as prefectures, municipalities, and school districts, but the improvements to these models have failed to improve residents' judgment in successful evacuation cases. We therefore analyzed the relationship between meteorological information and residents' disaster response and confirmed that they were strongly correlated and were contributing factors in preventing disasters. We revealed differences between a community's disaster prevention culture and the disaster information provided. This led us to propose a new concept in community disaster prevention that we call the "disaster response switch," which can serve as a data-driven risk management tool for communities when used in combination with advanced meteorological disaster information.
\end{abstract}

Kensuke Takenouchi

takenouchi.kensuke.3x@kyoto-u.ac.jp

1 Disaster Prevention Research Institute, Kyoto University, Uji Kyoto 606-0011, Japan
Keywords Community disaster prevention · Disaster response $\cdot$ High-resolution forecasting model $\cdot$ Japan $\cdot$ Meteorological information $\cdot$ Risk communication

\section{Introduction}

As the increased sophistication of early warning systems shows, the use of various types of disaster information is a crucial facet of recent measures against wind and flood damage. Most such systems collect and aggregate public information from specialized governmental and other organizations for information sharing, provide that information to the public, and help people respond to disasters (Zhu et al. 2011; Fang et al. 2015; Takahagi et al. 2015; Gojmerac et al. 2016; Usuda et al. 2017). Recently, there have been increasing opportunities for users to assist in the creation of relevant disaster information through the utilization of big data from social media and crowdsourcing (Aulov and Halem 2012; Xiao et al. 2015; Asakura et al. 2016; Qadir et al. 2016). Generally, however, there is a passive relationship between disaster information and the residents who receive disaster information and use it to take actions.

In Japan, a wide variety of disaster information has been generated under a basic structure in which public organizations transmit information (Japan Meteorological Agency 2018a), and residents receive and act on this information as appropriate. However, such a system is not necessarily effective in actual disaster scenarios. Improvements in disaster information exacerbate the problem of information dependency, in which people fail to act in the absence of disaster information (Katada et al. 2005; Yamori 2009). No matter the extent to which disaster 
information is improved and properly implemented, there are cases in which responses according to the assumptions described above do not materialize, and blame for the disaster is placed on the government, with victims claiming that the outcome was not as expected or that the administrative response was inadequate. In contrast, there have also been many successful evacuations during disasters. Investigations of such successful cases often reveal effective judgments made by local residents (communityspecific judgment criteria).

Based on the present situation in Japan, this study aimed to effectively apply disaster information-represented in particular by meteorological information at the local level-to search for methods of coordination with local disaster response situations. In general, the improvements in disaster information have been discussed by government officials or academic experts. This approach from the official disaster information could not improve the issues enough. This study did not aim to just consider improvements of meteorological information at the local level, but to research the possibility of improvements through residents' participation in providing meteorological information, and through the coordination of the two information sources for effective evacuation in communities.

Section 2 describes the methods used in this research, and Sect. 3 presents the results. In Sect. 3.1, we review the current status of the spatial resolution of weather forecasting models - that is the horizontal distance between grids of the models, which is the basis for improvements in meteorological information-and address the possibility of expressing various administrative scales such as country and city. In Sect. 3.2, we present some successful examples of residents evacuating during a disaster and examine how meteorological information was utilized for disaster prevention in these communities. In Sect. 3.3 we analyze the relationship between meteorological information and local disaster responses to investigate the role of high-resolution meteorological information in the response of residents to a disaster. In Sect. 4, we outline the importance of connecting meteorological information with communityspecific judgment criteria, propose a "disaster response switch" to promote effective coordination of response efforts, and discuss the improved application of meteorological information in future disasters.

\section{Methods}

This research examined how meteorological information is used in the coordination of local disaster responses from three viewpoints - expression of locality in meteorological information, the utilization of meteorological information by communities in successful disaster evacuations, and the applicability of the above coordination.

First, we reviewed the current status of horizontal resolution in weather forecasting models. The horizontal resolution is generally discussed in terms of the scales at which a meteorological phenomenon can be resolved. In this research, we applied administrative scales to meteorological information, focusing on what administrative divisions the models can resolve (for example, countries, prefectures, municipalities, school districts, and community associations). We investigated changes in the horizontal resolutions of the Japan Meteorological Agency (JMA) numerical forecast models over time and considered how current meteorological information can be used for disaster responses in communities (Sect. 3.1).

Next, we looked at how communities use meteorological information in disaster responses and investigated advancements in meteorological information through an examination of some recent disasters in Japan. We reviewed information that could be used to efficiently determine the necessity for evacuation in communities and compared the situation with actual cases. By examining successful evacuations during the heavy rainfall in northern Kyushu in 2017 and in western Japan in July 2018, we examined the factors considered when the decision to evacuate was made and whether meteorological information directly informed these judgment calls or not (Sect. 3.2).

Finally, we examined the relationship over time between meteorological information and disaster responses based on interviews with residents about the heavy rainfall in northern Kyushu in 2017. We used real-time hazard risk maps that show flooding, inland flooding, and landslides as examples of advanced meteorological information that can express locality, and compared when interviewees began to evacuate with this information. We attempted to improve disaster evacuations by adjusting their timing with respect to the disaster risk levels in the hazard risk maps. We also considered some issues related to residents' disaster responses and confirmed the applicability of more advanced meteorological information to disaster response at the community level (Sect. 3.3). Based on these three approaches, this research considered the importance and applicability of utilizing meteorological information when coordinating local disaster responses.

\section{Results}

Weather forecast models are used for meteorological information that can show possibilities of disasters. The meteorological information is expected to function effectively for residents' actions in disasters. In this section, we 
checked how weather forecast models can reflect local situations and how meteorological information was used for residents' action through actual disaster cases. In addition, we analyzed how the meteorological information could function for residents' evacuations.

\subsection{Locality of High-Resolution Weather Forecast Models}

Among the various types of information used during a disaster, meteorological information-primarily in the form of predicted and observed data-plays an effective role in advance disaster response. Improvements in weather forecasts play an important role in enhancing disaster risk management. With respect to the prospects of utilizing meteorological information for residents' disaster response, this section begins with a review of recent advancements in meteorological predictions from the perspective of spatial resolution.

Figure 1 shows the change over time in the horizontal resolution of the numerical forecast models used by the JMA for weather forecasting. The JMA computer predictions began in 1959. The horizontal resolution of the weather forecasting model used at that time was about $381 \mathrm{~km}$ and covered the northern hemisphere. A globalscale model with a horizontal resolution of $280 \mathrm{~km}$ came into use in 1987, and a mesoscale model with a horizontal resolution of $10 \mathrm{~km}$ began to be used in 1998 . Today, the

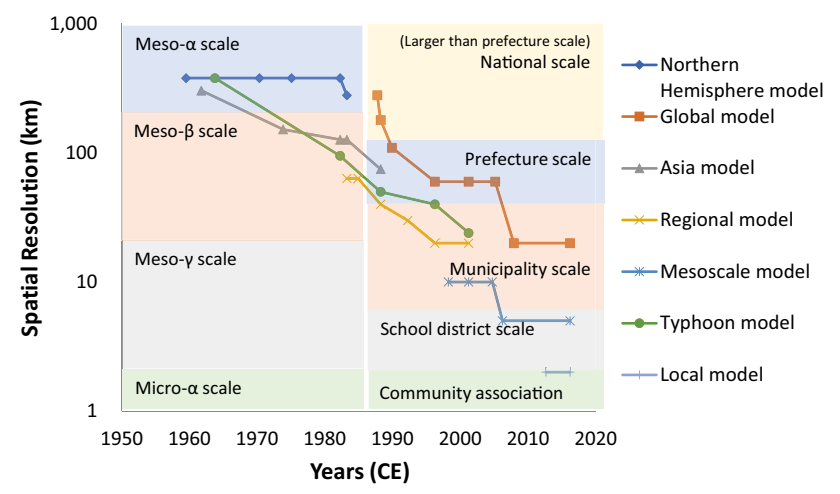

Fig. 1 Change over time of the spatial resolutions in the Japan Meteorological Agency (JMA) numerical weather forecasting models and the relationship between meteorological phenomena and administrative scale Source Forecast models (Japan Meteorological Agency 2020); prefectures and municipalities (Geospatial Information Authority of Japan 2014); school districts (Ministry of Education, Culture, Sports, Science and Technology 2015); community associations (Ministry of Internal Affairs and Communications 2013). Note Administrative scales are calculated in such a way that areas are approximated as a square and average coverage rates are maximized. Prefectural scales in Hokkaido are calculated for each subprefectural office (Hokkaido is much larger than other prefectures). School district and community association scales are calculated by averaging data for each prefecture. School districts use elementary schools as units
JMA uses its Global Spectral Model (GSM), Meso-Scale Model (MSM), and Local Forecast Model (LFM), with resolutions of 10,5 , and $2 \mathrm{~km}$, respectively. The JMA has also developed various forecast models such as the OneWeek Ensemble Prediction System (WEPS) and the Typhoon Ensemble Prediction System (TEPS) (Japan Meteorological Agency 2017).

Figure 1 also shows the relationship between the spatial scale of meteorological phenomena and the administrative scales of prefectures, municipalities, school districts, and community associations in Japan. Administrative scales vary with the country or region. Surface areas that represent scales for the country, prefectures, municipalities, school districts, and community associations are approximated as squares for calculations. Actual scales are $615 \mathrm{~km}$ at the national level, $43-124 \mathrm{~km}$ for prefectures, and $2-47 \mathrm{~km}$ for municipalities. School districts and community associations are averaged according to the number of schools and community associations in each prefecture, resulting in approximations of $1.3-8.7 \mathrm{~km}$ and $0.4-2.3 \mathrm{~km}$, respectively. Due to this overlap in scales, Fig. 1 uses maximal average coverage rates. Administrative scales largely differ according to the country or region, so we limit discussions here to the case of Japan. Numerical prediction models at the school district and community association scales have appeared only recently in the development of weather forecasting models in Japan, and it has been possible to use numerical forecasting models and meteorological information as information for evaluating local characteristics. The horizontal resolution of operational short-term forecast models in other countries is also approximately several kilometers (Saito et al. 2007; Dudhia 2014; GDPFS 2015).

Advanced computing environments have greatly improved the spatial resolutions of current numerical forecasting models, and in the near future it will be possible to use results from weather forecasts for smaller geographic regions. The spatial resolution of meteorological information in Japan is as fine as $1 \mathrm{~km}$ for hazard risk maps and $250 \mathrm{~m}$ for high-resolution "nowcasts" created using radar information, so that locality can now be sufficiently resolved. Accordingly, advanced meteorological information can be taken into account when considering local disaster risk. These increases in the resolution of weather forecasting models are expanding the application range for forecasting results. Benefits have been realized in a wide variety of fields, including energy, urban planning, climate science, and agriculture. To meet customer needs, these fields do not merely provide meteorological information-they also provide meteorological information as a service, including consulting that incorporates this information. 


\subsection{Utilization of Meteorological Information in Successful Community Disaster Responses}

In disaster response, many surveys on disaster awareness have been conducted (Siebeneck and Cova 2012; Alcántara-Ayala and Moreno 2016; Castro et al. 2017), and factors of risk perception and its processes have been discussed (Kurokawa and Seiwa 1986; Oikawa et al. 2005; Ho et al. 2008; Gierlach et al. 2010; Su et al. 2015; Tanaka et al. 2015; Wei et al. 2016). While many disaster risk awareness studies have discussed the importance of understanding disaster risks within the community, such assumptions often do not hold in actual disaster cases, which show weak relationship between the understanding and disaster responses.

Floods occur every year in Japan at varying scales (Ministry of Land, Infrastructure, Transport and Tourism 2018). However, the evacuation rate is often less than $10 \%$, and the low level of evacuation awareness has been regarded as a big issue in disasters. To improve this situation, several surveys have been conducted regarding the effectiveness and utility of meteorological information during disasters in Japan, and generally positive results have been obtained (Fukunaga et al. 2014; Japan Meteorological Agency 2018b, and other earlier surveys on the utility of meteorological information conducted by the Japan Meteorological Agency). Other studies have investigated the degree of intent to respond based on meteorological information (Katada et al. 1998; Kodama et al. 2014; Ushiyama 2014; Oikawa and Katada 2016), but these surveys have only been conducted during normal times, so it remains unknown whether they are applicable to actual disasters. Other studies have examined what information could be applied to evacuations during actual disasters. A survey on the 2013 Izu Oshima sediment disaster reported that the rate of evacuation based on meteorological information was about 10\% (Kaziya et al. 2018). In a survey conducted to investigate the response to the heavy rainfall in July 2018, less than 10\% of the respondents answered that they used meteorological information when deciding whether to evacuate, and $46 \%$ answered "none in particular" (Working group on evacuations from water-related disasters, landslides, and debris flows caused by the heavy rainfall in July 2018). Not enough utility of meteorological information was also reported in other cases (Kakimoto and Fujimi 2013; Kusano et al. 2015; Yasumoto et al. 2018). Kobayashi and Tanaka (2017) analyzed the relationship between residents' responses and knowledge related to each disaster process through a questionnaire survey during the 2015 Kinugawa River flood, and especially how the low knowledge level led residents not to show any increase of evacuation intention even if they got disaster information.
Improved meteorological information does not appear to be effective enough, despite the fact that most people believe it is useful information to have during a disaster (Japan Meteorological Agency 2018b). Some survey results related to the use of meteorological information during actual disasters have been confirmed, but there are few cases where meteorological information has actually been used to determine local disaster responses. We need to consider what factors contribute to determinations regarding local disaster responses, especially those related to evacuations. Disaster surveys cover regions in which human casualties occurred, but also indicate regions in which evacuations were successful and resulted in no human casualties.

Table 1 presents some examples of successful evacuations during two recent disasters, both of which resulted in extensive damage. Cases 1 and 2 are from flooding due to heavy rainfall in northern Kyushu that occurred on 5 July 2017. During that disaster, sustained heavy rainfall $(100 \mathrm{~mm} / \mathrm{h})$ caused flooding damage, primarily along tributaries to the Chikugo River (Japan Meteorological Agency 2018c). Muddy streams containing driftwood and soil flooded villages, resulting in 43 dead or missing persons. While evacuation information is important in such localized and short-lived heavy rainfall disasters, it is also important for residents themselves to be aware of and quickly respond to dangers in the area. In Case 1, muddy waters that contained sediment flooded the Hiraenoki district of Asakura City in Fukuoka Prefecture (Fig. 2a). During that crisis, however, evacuations started as a result of ground-floor flooding of houses adjacent to a small stream in the district, and all 92 people in 37 households survived. In Case 2, rains in the Fukiage district of Hita City in Oita Prefecture on 5 July 2017 grew stronger in the afternoon and continued until evening, causing areas around the Kagetsu River to flood. The Fukiage district had experienced flooding due to heavy rainfall five years earlier, so thorough response actions had been put in place and the district acted accordingly. As a result, the district experienced only minimal damage.

Cases 3-5 describe successful evacuations during heavy rainfall that occurred on 5-8 July 2018. This heavy rainfall event featured long-lasting rain over an extended time across the whole of western Japan, with record 72-hour rainfalls recorded at 123 locations (Japan Meteorological Agency 2019). Landslides and flooding resulted in 232 dead or missing persons. In Case 3, local fire brigades in the Kamiotomi district of Kyotamba-cho in Kyoto Prefecture realized they were experiencing unprecedented rainfall, and evacuated residents in crisis. As Fig. $2 b$ shows, a small river flows immediately next to the homes in the community. The river quickly flooded at 6:00 a.m., presenting a dangerous situation. In Case 4, an upstream 
Table 1 Cases of successful community evacuations in Japan

\begin{tabular}{|c|c|c|}
\hline $\begin{array}{l}\text { Case } \\
\text { No. }\end{array}$ & Area & Overview \\
\hline 1 & $\begin{array}{l}\text { Hiraenoki, Asakura City in Fukuoka } \\
\text { Prefecture (Fig. 2a) }\end{array}$ & $\begin{array}{l}\text { Rain suddenly began falling on the afternoon of } 5 \text { July } 2017 \text {. A stream in the village crested } \\
\text { its banks, flooding the ground floors of adjacent houses. This was similar to what happened } \\
\text { during heavy rainfall five years before, but the rains were even heavier this time, and the } \\
\text { residents themselves decided to evacuate. The village was inundated with muddy water a } \\
\text { few hours later. }\end{array}$ \\
\hline 2 & Fukiage, Hita City in Oita Prefecture & $\begin{array}{l}\text { In the evening of } 5 \text { July } 2017 \text {, continual rains caused the adjacent Kagetsu River to overflow. } \\
\text { Residents had already established a thorough response as a result of flooding five years } \\
\text { before. Considering the current situation to be similarly dangerous, residents evacuated, } \\
\text { including assisting the elderly, and as a result the only damage was partial flooding. }\end{array}$ \\
\hline 3 & $\begin{array}{l}\text { Kamiotomi, Kyotamba-cho in Kyoto } \\
\text { Prefecture (Fig. 2b) }\end{array}$ & $\begin{array}{l}\text { At } 6: 00 \text { a.m. on } 7 \text { July } 2018 \text {, the local fire brigade took note of abnormal rain and began a } \\
\text { door-to-door call for evacuation. A landslide caused evacuation parties to split in two, but } \\
\text { all remaining residents were successfully evacuated to a temple on higher ground and no } \\
\text { lives were lost. }\end{array}$ \\
\hline 4 & $\begin{array}{l}\text { Kawaharada, Shiso City in Hyogo } \\
\text { Prefecture }\end{array}$ & $\begin{array}{l}\text { On } 7 \text { July 2018, a telephone call from a resident living in the upstream area notified officials } \\
\text { of an accumulation of fallen trees, so evacuees at a community center were relocated to } \\
\text { higher ground. The community center was inundated immediately afterward (NHK 2018). }\end{array}$ \\
\hline 5 & $\begin{array}{l}\text { Takahama, Matsuyama City in Ehime } \\
\text { Prefecture }\end{array}$ & $\begin{array}{l}\text { Volunteer disaster prevention organizations that began patrols in the afternoon of } 6 \text { July } 2018 \\
\text { noticed landslides and the like, and began a door-to-door call for evacuations. Further } \\
\text { landslides occurred at } 35 \text { locations in the district the following morning, but no lives were } \\
\text { lost (Isouchi 2018). }\end{array}$ \\
\hline
\end{tabular}

*Cases 1, 2: Heavy rainfall in northern Kyushu in 2017; Cases 3-5: Heavy rainfall in July 2018

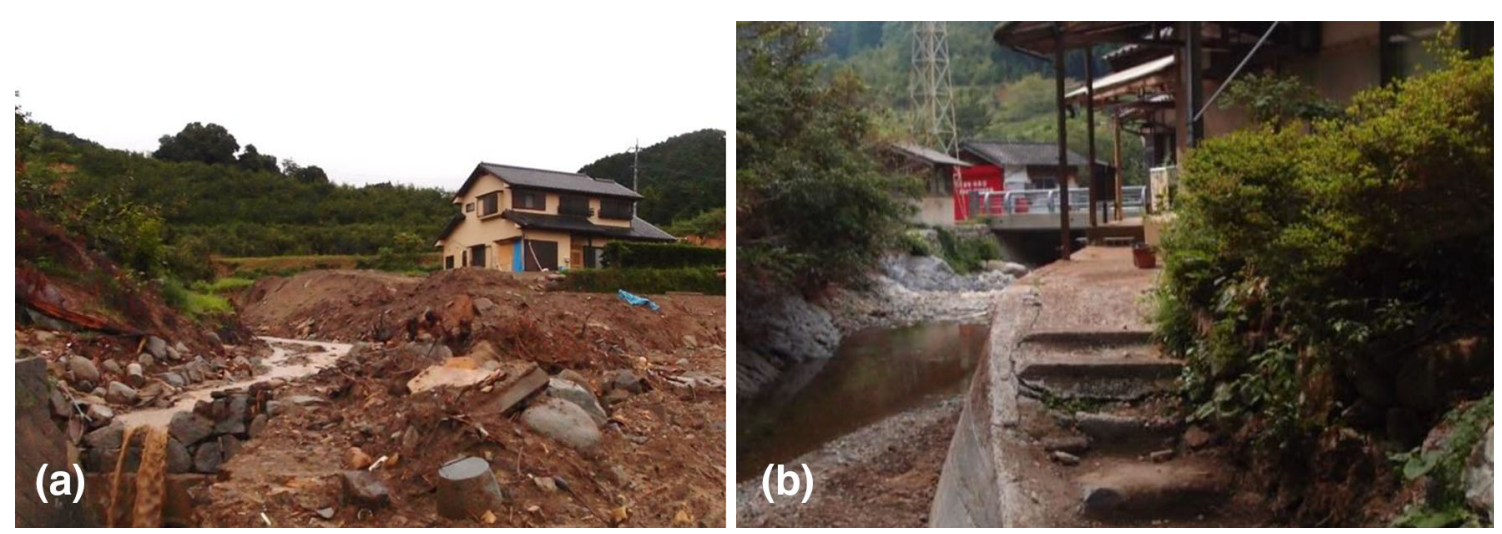

Fig. 2 Areas with successful evacuations in Japan. a Hiraenoki, Asakura City in Fukuoka Prefecture (Case 1); b Kamiotomi, Kyotamba-cho in Kyoto Prefecture (Case 3). Photograph by a Takenouchi, 7 September 2017; and b Takenouchi, 30 August 2018

landslide in the Kawaharada district of Shiso City in Hyogo Prefecture caused an accumulation of fallen trees. This information was shared within the district, leading to an evacuation before a large flood occurred. In Case 5, residents in the Takahama district of Matsuyama City in Ehime Prefecture, which had seen no recent disasters, evacuated after noticing small-scale anomalies the day before any damage occurred, saving them all.

Many successful cases of evacuation during disasters are the result of some type of trigger that prompted the start of evacuations. While various kinds of meteorological information were announced in these cases as well, there were few cases where early evacuations in communities were triggered by information indicating the potential for disaster. Evacuation information from local government (evacuation order, evacuation advisory, and evacuation preparation information in Japan) is issued when local government judges the necessity of residents' evacuations. However, most residents do not tend to evacuate, even if evacuation information is issued. The evacuation rate is low in most cases. At present, evacuation information is mainly judged based on a guideline for evacuation information issues. In Japan, it is a basic procedure that local governments judge evacuation information based on 
meteorological information and residents evacuate based on this information, but this flow is likely to stop at the step of residents' evacuations. The consideration of coordination between meteorological information and residents' evacuations is very important to ensure that residents are able to evacuate smoothly.

Takenouchi et al. (2018) surveyed the disaster response in areas affected by the heavy rainfall in northern Kyushu in 2017 and analyzed factors related to successful evacuation in Cases 1 and 2. The Hiraenoki district (Case 1) is a village (population 94 in 2015) located in a mountainous region alongside the medium-sized Hira River. From the survey results of the Hiraenoki area, we first confirmed that no disaster prevention activities such as evacuation training had been conducted in the area. The proportion of elderly residents was high, and the responses from the interviewees suggested that the residents had relatively low disaster awareness in day-to-day lives. How is it, then, that we see a successful evacuation case, with no human casualties, coming from a community with such low disaster awareness? The survey indicated that the successful case of Hiraenoki is related to several factors.

The stream in Hiraenoki had previously flooded during heavy rainfall five years before, causing adjacent houses to be flooded at the ground-floor level. The damage was even more severe in the 2017 event, with several houses washed away by the muddy water. In that event, however, the level of the stream flowing through the town and the flooding of adjacent houses served as judgment criteria for evacuation. The ground-floor inundation of houses along the stream, together with the continued rainfall, served as a trigger for evacuation, during which the community cooperated and everyone was saved.

We also confirmed a social environment in Hiraenoki district in which the experience from five years before was not easily forgotten, in particular the sense of community developed through daily interactions with others in the community. In Hiraenoki, there is regular agricultural collaboration related to persimmon agriculture. During the heavy rainfall five years before, community residents worked together to stack sandbags to prevent the flooding of homes alongside the stream, which later served as a judgment criterion for evacuation-having performed that coordinated task, the residents' awareness of this heavy rainfall experience had not eroded five years later, and the inundation of houses became a community-specific judgment criterion for disaster response leading to awareness of the need to evacuate.

The Fukiage district (Case 2) is a village (population 931 in 2015) alongside the medium-sized Kagetsu River. When revising its disaster response plan to better respond to an actual disaster, this district applied its experience from five years before when the Kagetsu River overflowed.
As a result, each group within the district was able to conduct their own organized response, relying on their sense of the normal flow of the Kagetsu River through the district as a judgment criterion when the water began to rise. Regional cooperation has long been an important cultural characteristic of the Fukiage area, and residents are very conscious of this. Through this sense of unity, residents quickly mobilized when they sensed danger, when the normal behavior of the Kagetsu River suddenly changed.

However, meteorological information itself has not been directly applied to determining evacuation behavior in such areas. In the Fukiage area we heard remarks like "we don't need water level information; we can see the river from our windows." While this is an understandable sentiment, such statements are indicative of low awareness with respect to the utilization of meteorological information for disaster response activities. When considering local flood disaster response, community-specific judgment criteria potentially exist in these areas and function accordingly during disasters.

Even when meteorological information is not completely effective, there are cases where local disaster prevention culture plays a major role in coping with disasters. Efforts are being made at various locations in Japan to respond to local flooding (Cabinet Office 2005). Examples of local initiatives conducted in the past include those slightly different from typical disaster prevention efforts, such as the distribution of manju (bean cakes) in Nagasaki in remembrance of past disaster victims (Takahashi 2014), as well as more conventional "hard" efforts such as the creation of emergency supply stores located on higher ground (Kayano 2001). In addition, while disaster information has been enhanced as a "soft" measure in recent years, there are also efforts toward creating communityspecific information in an attempt to produce a modern version of a disaster prevention culture. Examples include reconsidering the importance of community-specific information to identify local precursory phenomena of disasters and thereby establish evacuation rules (Katada and Kanai 2010), appointing observers to monitor the local situation (Sayo-cho Tropical Storm Etau Disaster Investigation Committee 2010), and examining locally important meteorological information (Takenouchi et al. 2015). Community-based disaster management (CBDM) and public participation are becoming more important as approaches to promote community involvement in disaster management (Buckland and Rahman 1999; Pearce 2003; Chen et al. 2006; Zhang et al. 2013; Chou and Wu 2014; Engel et al. 2014; McLennan 2018). However, in recent years in Japan there have also been fears of a worsening local disaster prevention culture due to declining birthrates, an aging population, and the improvement of disaster 
information from specialized organizations. In some cases, successful evacuations can be regarded as the functioning of one form of local disaster prevention culture. When considering local disaster response support based on meteorological information, it is important to investigate what factors were present at that time and why evacuations in that area were successful. Individuals' evacuations are influenced by various factors such as age, gender, family, health condition, or area, so that practical decisions to evacuate are complex. However, common judgements in communities' evacuations are based on disaster prevention culture, past disaster experience, and evacuation rules.

\subsection{Relationship between Meteorological Information and Residents' Disaster Responses}

When using high-resolution meteorological information to produce meteorological information at resolutions close to the community association scale, how can these high resolutions be applied to disaster response in these communities? The successful evacuation cases reviewed above present major issues related to how refinements of meteorological information, which have previously been pursued without question, can actually be utilized in disaster responses in local communities. The question is how meteorological information can be effectively applied to local communities.

In this section, we focus on seven cases in the heavy rainfall in northern Kyushu in July 2017 (including Hiraenoki and Fukiage districts) based on our interviews with residents to determine the relationship between meteorological information and residents' decision to evacuate. We also focus on differences in considerations of meteorological information and local disaster response, allowing us to predict forms of meteorological information that can be effectively applied during disasters by analyses of the relationship between high-resolution meteorological information and residents' actual disaster response. We organized the relationship by district based on the residents' responses to the survey conducted by Takenouchi et al. (2018).

The survey was conducted on 7-8 September 2017, two months after the heavy rainfall. The first author visited residents' houses and conducted face-to-face semistructured interviews for about one hour with residents who were well acquainted with the regional situation at the time. The primary survey items were "community-specific initiatives and judgment criteria during the disaster" and "response states during the disaster." Because this survey was not conducted to quantitatively analyze local disaster response, but to grasp the state of regional efforts and disaster response at the time, we placed no particular limits on the number of people surveyed, including for gender or age. However, interviews focused mainly on those residents who grasped the situation of the overall district at the time, and as a result participants were primarily resident association leaders and welfare commissioners. Resident associations in Japan play roles in community disaster prevention, so the association members were selected as interviewees as much as possible to grasp the situations of disaster responses in the communities. The survey area is shown in Fig. 3 and the survey participants and damage situations are listed in Table 2. The survey areas, except for Fukiage district, are located in mountainous areas, and about $40 \%$ of the population was over 65 years old.

We examined the relationship between survey responses and improved meteorological information-in particular the relationship between increased resolution of meteorological information and local disaster prevention-and considered three types of disaster prevention-related meteorological information that represent the highest resolution meteorological information currently available in Japan: hazard distribution information of flood warnings; heavy rain warnings (inland flooding damage); and

Fig. 3 Study survey area in Japan Source Created by the authors based on Geospatial Information (GSI) tiles (Seamless photo maps) (Geospatial Information Authority of Japan 2018)

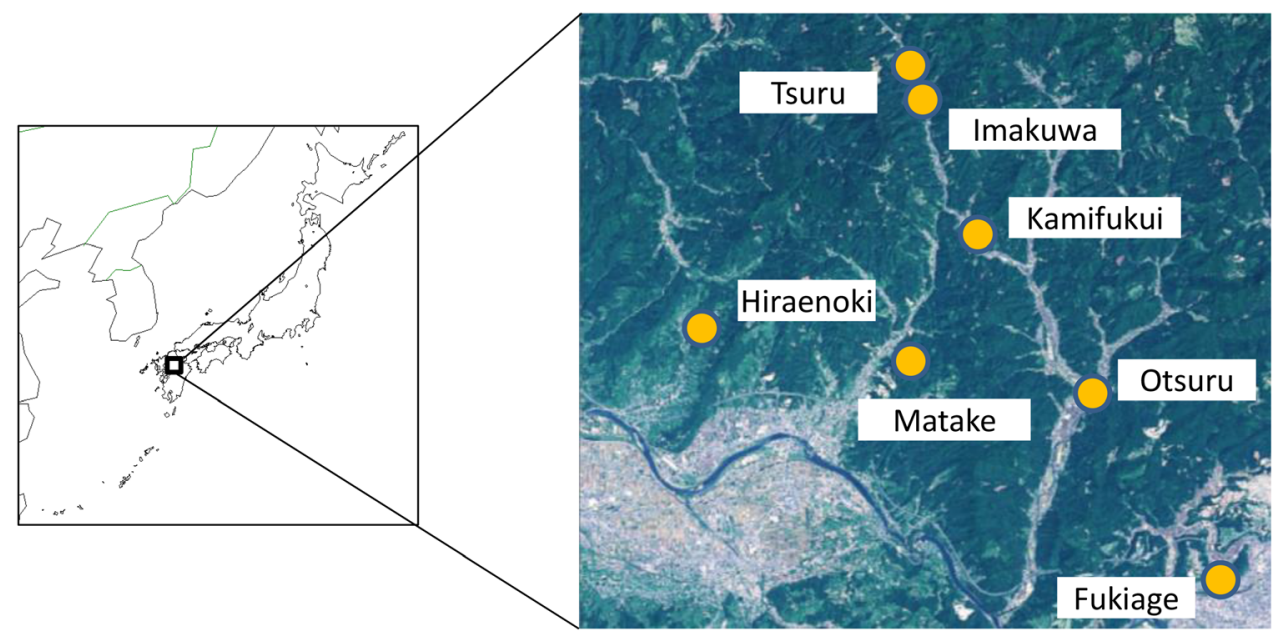


Table 2 Outline of the survey participants and damage situations in the communities in the study survey area in Japan

\begin{tabular}{|c|c|c|}
\hline $\begin{array}{l}\text { Area (Population in } \\
\text { 2015) }\end{array}$ & Survey Participants & Damage Situations in Communities \\
\hline $\begin{array}{l}\text { (1) Hiraenoki district in } \\
\text { Asakura City (94) }\end{array}$ & 1 welfare commissioner and 1 general resident & $\begin{array}{l}\text { Some houses inundated, directly damaged by } \\
\text { landslides, or washed out by overflow }\end{array}$ \\
\hline $\begin{array}{l}\text { (2) Matake district in } \\
\text { Asakura City (34) }\end{array}$ & 1 welfare commissioner and 2 general residents & $\begin{array}{l}\text { Some houses inundated, directly damaged by } \\
\text { landslides, or washed out by overflow }\end{array}$ \\
\hline $\begin{array}{l}\text { (3) Otsuru district in } \\
\text { Hita City (1531) }\end{array}$ & A president of a resident association & $\begin{array}{l}\text { Some houses inundated, directly damaged by } \\
\text { landslides, or washed out by overflow }\end{array}$ \\
\hline $\begin{array}{l}\text { (4) Fukiage district in } \\
\text { Hita City (931) }\end{array}$ & A president of a resident association and 1 general resident & Some inundated houses around a downstream area \\
\hline $\begin{array}{l}\text { (5) Kamifukui district } \\
\text { in Toho-mura (207) }\end{array}$ & A president of a resident association & $\begin{array}{l}\text { Some houses inundated and directly damaged by a } \\
\text { landslide }\end{array}$ \\
\hline $\begin{array}{l}\text { (6) Imakuwa district in } \\
\text { Toho-mura (73) }\end{array}$ & 1 member of a resident association and 1 general resident & Landslides, but no direct damages to houses \\
\hline $\begin{array}{l}\text { (7) Tsuru district in } \\
\text { Toho-mura (100) }\end{array}$ & $\begin{array}{l}1 \text { resident who assumed supports for nearby aged people to } \\
\text { evacuate, } 1 \text { supported resident, and } 1 \text { general resident }\end{array}$ & $\begin{array}{l}\text { Some houses inundated by water stream from } \\
\text { mountains and directly damaged by a landslide }\end{array}$ \\
\hline
\end{tabular}

Fig. 4 Hazard risk maps for a landslides; b inland flooding (short-term heavy rainfall); and c flooding (small and medium rivers) in the Asakura City, Japan area as of 17:30 on 5 July 2017 (a)

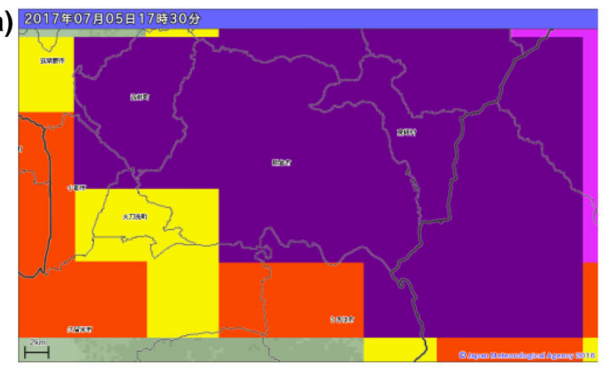

(c)

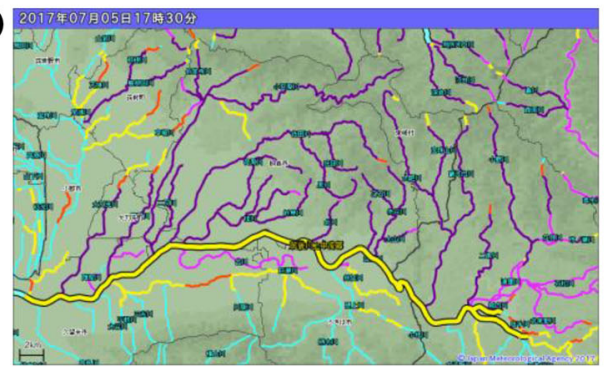

(b)

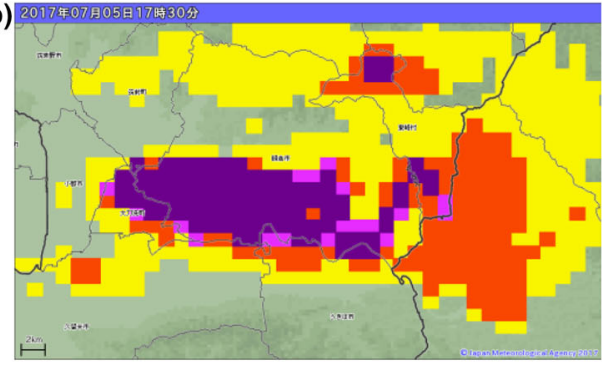

High

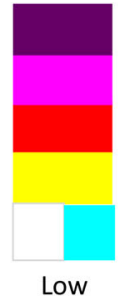

Level 5: Extreme risk

Level 4: High risk

Level 3: Warning

Level 2: Caution

Level 1: Check weather bulletin landslide disaster warnings (collectively referred to below as "hazard risk maps"). This high-resolution hazard risk map currently has a spatial resolution of $1 \mathrm{~km}$ (although only 5-km resolution for hazard risk maps for landslide warnings was available at the time), so this information can represent hazard levels for each area. The information is divided into five levels, with darker colors indicating increased hazard (Fig. 4). This information is normally used for issuing advisories and warnings, generally with advisories issued at the second level, warnings issued at the third level, evacuation information issued at the fourth level, and actual disaster occurrence or its extremely high possibility at the fifth level.

Based on the survey results from the seven districts, Fig. 5 shows a time series of when interviewees began evacuating, together with each risk level from the hazard risk maps. Interviewees in the Otsuru, Kamifukui, and Imakuwa districts did not evacuate.

The status of the hazard risk map for each district and the evacuation start times for the interviewees (green color) are confirmed, with a focus on the time at which the disaster risk reached Level 4 or higher (light or deep purple colors), which is the standard for evacuation. In Fig. 5, the evacuation times in the Hiraenoki, Fukiage, and Tsuru districts were around or a little later than the times that some risk surpassed Level 4. In the Matake district, evacuation began much later. The Hiraenoki and Matake districts are located near each other, so the hazard risk maps for these districts show similar changes. According to the interviewees in each district, the residents in the Hiraenoki 


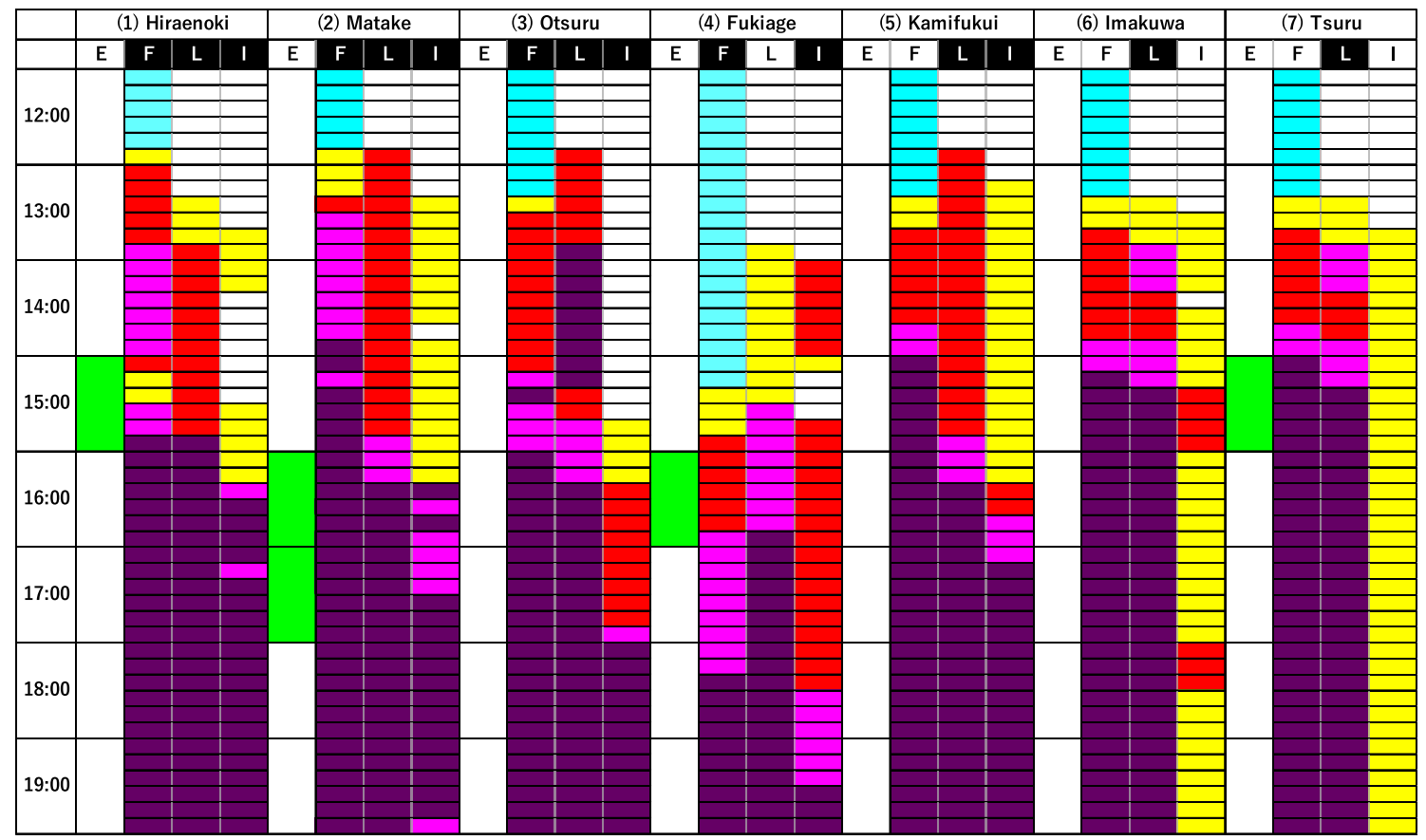

Fig. 5 Relationship between meteorological information and evacuation timing in the affected area during the disaster from heavy rainfall in northern Kyushu, Japan on 5 July 2017. E: evacuation (green); F: flooding; L: landslides; I: inland flooding. Empty

district began to discuss the disaster risk around 13:00 and began evacuation around 15:00, but in the Matake district evacuation began later, between 16:00 and 18:00, depending on individuals. The resident association in the Fukiage district called for evacuation to general residents upon checking local situations after 16:00. The residents in the Tsuru district began to discuss the disaster risk around early 13:00 and took some evacuation response measures such as moving some cars to safe areas or helping older neighbors to evacuate. The interviewees in other districts could not evacuate. The interviewee in the Otsuru district was unable to evacuate due to his delayed action. In the Kamifukui district, the decision to evacuate was made by individual residents, only a few of whom actually evacuated. The interviewees in the Imakuwa district explained that the situation around the district was dangerous at 14:00 for aged people. The Imakuwa and Tsuru districts are located near each other, but differences of residents' evacuations were confirmed as the Hiraenoki and Matake districts. In all these districts, after certain risks surpassed Level 4, residents observed phenomena that indicated one or more of the disasters listed in Table 2, including overflow from gutters or inundated houses.

This confirms that disaster types and degrees of danger are represented according to the unique characteristics of each district, even those that are separated by only a few kilometers. In the Hiraenoki, Fukiage, and Tsuru districts, evacuation columns indicate that interviewees did not evacuate. Black indicates particularly related disasters (see Table 2). Cell colors in the flooding, landslide, and inland flooding columns indicate the risk level for the respective area at the time (see Fig. 4)

it was possible to begin evacuating safely when one or more risks were at a relatively low level. In other districts, however, it was confirmed that evacuation was not possible because one or more risks had reached the dangerous Level 5 stage.

The hazard risk map was deep purple, indicating "Level 5: extreme risk," in all regions at stages when evacuation became difficult. Light purple, indicating "Level 4: high risk," provided information that was effective up to the point at which evacuation became necessary. This shows that with the hazard risk maps, evacuations were conducted under less dangerous conditions in areas where evacuation measures were encouraged before risks reached Level 5. Evacuation behavior can be improved if hazard risk maps with high local resolution are appropriately used. The examined cases indicate that if hazard risk maps are successfully used, it becomes possible to conduct evacuation responses in advance, even when there are no communityspecific judgment criteria or when such criteria are not shared. However, we confirmed no situations in which the hazard risk map was actually used. The interviews in Takenouchi et al. (2018) mention virtually no cases in which meteorological information for disaster prevention was applied to local disaster response, the only exceptions being rainfall forecasts in the Hiraenoki district and live cameras showing the upstream state of the Kagetsu River in the Fukiage district. Use of the hazard risk map was not 
confirmed, and even where it was used, such use was likely limited to personal utilization by an extremely limited segment of the local population.

\section{Discussion}

Current high-resolution meteorological information may effectively facilitate local evacuation behavior during an actual disaster. However, most successful evacuation cases in our study were not based on meteorological information, and meteorological information is not being fully utilized for regional disaster prevention at present. In this section, we use these results to indicate differences between meteorological information and local disaster response from the viewpoint of local utilization, to propose measures for mutual cooperation and to discuss what role improvements in meteorological information should play.

\subsection{Fundamental Differences between Meteorological Information and Community-Specific Judgment Criteria}

What factors allowed some districts to carry out emergency responses leading to evacuations at the early stages of a disaster? Takenouchi et al. (2018) presented "communityspecific judgment criteria" as one such factor, describing the effects of differences in existing meteorological information and local criteria. In regions where evacuations proceeded early, there existed some criteria for regional judgments. These characteristics are considered as "the existence of a shared recollection of a disaster and a social environment conducive to subconsciously passing on that recollection" (Takenouchi et al. 2018, p. I_37) and are important elements for awareness of disaster risk within an area. However, the characteristics of disaster information are very different from the characteristics of local disaster prevention culture and include "disaster risk recognition that relies on personal understanding and an information environment that emerges only during disasters" (Takenouchi et al. 2018, p. I_37). If disaster information is not used in a way that represents the common disaster risk awareness in the community, its use is basically left to individual judgments, and those judgments define recognitions of disaster risk. These judgments are forced upon individuals along with the announcements of disaster information. This results in different disaster responses within the community, as shown in delayed actions or no evacuations in Fig. 5, which rely on individual judgments.

The successful evacuations identified in our study confirm another characteristic. Community-specific judgment criteria functioned in each case listed in Table 1, but Cases 3-5 are districts that have experienced no major disasters in recent years, so while some precursory phenomena similar to "the existence of a shared recollection of a disaster" were confirmed, the factors of "a social environment conducive to subconsciously passing on that recollection" were weak. This region can be characterized as one in which persons who are trusted in the region-such as firefighters, local acquaintances, and members of volunteer disaster prevention organizations-function as a communal knowledge reservoir instead. In areas like those in Cases 1 and 2 that experienced disasters five years ago, the residents have internalized objective experiences related to past disasters as information worth acting on. Areas like those in Cases 3-5 have not experienced disasters in recent years, but indications from persons and organizations that are trusted by local residents turn out to function as substitutes for objective past experience. The fact that meteorological information does not function as a communityspecific judgment criterion suggests that this information is not trusted or not recognized as worth acting on.

\subsection{The Role of Coordination and the Proposal of a Disaster Response Switch}

Elaborated spatial resolution of meteorological information allows the expression of phenomena at the community association scale. Early warning systems and other forms of official evacuation information continue to be improved and enhanced. However, while meteorological information from some actual disaster cases can be put to good use, we can find few cases where meteorological information could be utilized for disaster responses in communities. This situation is the result of differences between meteorological information and residents' responses. When community-specific judgment criteria are effective, response actions are taken in accordance with those criteria, even when disaster information is not announced or is difficult to obtain, leading to evacuation actions at a relatively early stage. In contrast, when regional response activities are unclear, leaving disaster response up to individual judgment, differences in the timing of disaster recognition among individuals may delay evacuations. The interviewees in the Matake district, for example, began disaster evacuations not according to the judgment of the community but based on the judgment of individuals. This led to differences in when residents began to evacuate. Accordingly, some residents were able to evacuate early, whereas others were not able to evacuate at all. The interviewees explained that the situation in the area was extremely dangerous when the evacuation was started (see Fig. 5). In contrast, we confirmed a certain correspondence between meteorological information and response behavior based on community-specific judgment criteria in cases such as the Hiraenoki and Fukiage districts (see Fig. 5). Based on 
these results, high-resolution meteorological information can be applied to support disaster responses in communities. However, simply relaying meteorological information as natural science information may not have a sufficient impact on the local response behavior during disasters.

What is important is the construction of a social system that links the two. We suggest a "disaster response switch" as a candidate for such a system. The disaster response switch is what will trigger a local transition from daily-life mode to disaster-response mode. For self-preservation, various members including residents (for example, local governments, resident associations, general residents, and so on) would consider the timing of local disaster responses in advance by utilizing local disaster signs (past experiences and precursor phenomena that portended past disasters) and various types of current disaster information (meteorological information, hydrological information, and so on). If as in the case of the Hiraenoki district, for example, we use house inundation as an indicator for evacuation, we would consider the state of risk distribution information in such a situation, and if the risk of flooding rises or surpasses Level 4, we can predict that the result will be flooded homes and thus it is time to begin evacuating. In this way, a combination of unique local characteristics and meteorological information can be used as criteria to begin disaster responses. While enhanced disaster information in Japan has raised the issue of overreliance on information, resulting in people not acting until information reaches them, the disaster response switch would reestablish the lost independence of local judgmentmaking by residents who have neglected considerations of the relationship between the area and regional meteorological information, and promote the use of meteorological information for disaster response in the region. It can also mutually complement community-specific judgment criteria and meteorological information.

Judgments based only on past cases and the experiences of residents may lead to a sense of false security and failure to update local disaster risk assessments. Yet in recent years, we have experienced unprecedented disasters due to 100-year rainfall events, and there are fears that global climate change will lead to other extreme phenomena (IPCC 2012). Therefore, it is important to consider actions in the event of a disaster beyond that which has previously been seen. Meteorological information can play an important role in this regard because it can provide advance warning of disasters that exceed local judgment criteria, and even when the content and accuracy of judgment criteria are unclear due to a lack of experience with disasters, it is still possible to convey the potential for danger with some accuracy. Reliability as "information worth acting on" can be expected from information based on objective evaluations.
In contrast, it is difficult to use meteorological information alone to determine the characteristics of a region that qualify as community-specific judgment criteria. When residents use the disaster response switch to indicate highly localized disaster features, it becomes possible for those creating meteorological information to consider what types of information should be provided for regional disaster prevention.

\subsection{The Role of Improved Resolution of Meteorological Information in Disaster Response}

Improvements in meteorological information have so far been achieved through approaches such as refining models, enhancing resolutions, and increasing the number of members in ensemble forecasts. Enhanced resolution improves prediction accuracy, further refines expressible natural and social phenomena, and can greatly change the perception of meteorological information. The fact that we can discuss a coordination policy such as the disaster response switch is greatly influenced by improvements in the spatial resolution of meteorological information. Recent operational weather forecast models have resolved meso-alpha-scale phenomena, which will undoubtedly lead to discussion about the relationship between such information and community-specific judgment criteria. Resolution at the meso-gamma scale cannot convey differences between communities, limiting discussion to the municipality level. Continuous efforts toward developing weather forecast models have resulted in coordination between meteorological information and disaster responses in each community, leading us to the present situation where we can discuss a new coordination system such as the "disaster response switch." Previously, improved resolution of meteorological information aimed to meet resident needs that could not be sufficiently achieved by conventional means.

It is important to investigate further resolution improvements, but with regard to local disaster response, and it is also important that local communities be able to evaluate the expressiveness of community-specific disaster risks as shown in high-resolution meteorological information. To that end, it is necessary to consider how to use meteorological information to support the establishment of a disaster response switch. Different areas contain various risks, not all of which are observed and understood by administrators. Local residents themselves may be the most suitable observers for some risks, as seen in the successful evacuation cases. Increased resolution of meteorological information would be a form of technology that would support local disaster response by evaluating communityspecific risk information that may be difficult for 
administrators to understand and support. The establishment of a disaster response switch should lead to the investigation of the relationship between improvements in meteorological information and local disaster prevention, and is a process for extracting the significance of and problems related to increased resolution. In this respect, the role of high-resolution weather forecasting in local disaster prevention is more important than ever.

There are also issues related to enhanced resolutions. One such problem is the accuracy of predictions. It is important to verify whether the results of a high-resolution prediction model can properly evaluate regional characteristics. Regarding the hazard risk map in the Imakuwa district, there was information that the risk for a landslide disaster had risen strongly at Level 4, so risk level was not appropriately shown for some regions. This is related to the issue of standards setting, but also to the extent to which meteorological information can express locality. Another problem is increased reliance on meteorological information. Enhancing information increases reliance on that information, thereby possibly precluding discussions based on subjective observations in the region. All of these issues can be addressed through the creation of disaster response switches. This is because discussing disaster phenomena in the area can increase residents' understanding and awareness of hazard risk maps, thereby leading to an understanding of what each level means for that district. In this way, the disaster response switch can be linked to local criteria and meteorological information while compensating for other shortcomings.

\section{Conclusion}

In this research, we focused on meteorological information, a type of disaster information that plays an especially important role in storm, flood, and landslide response, and we evaluated improvements in the spatial resolution of meteorological information. We confirmed that while detailed hazard information is currently being released at the community association scale, meteorological information is at present insufficiently used in local disaster response. We performed analyses of the relationship between meteorological information and the response action of residents during heavy rainfall in northern Kyushu in 2017, showing the potential for coordination between meteorological information and local disaster response.

Based on our results, we propose a social system that we call the "disaster response switch," which can work as a data-driven risk management tool for communities. It can be developed through the coordination of meteorological information and local-judgment criteria for disaster response. The disaster response switch can improve residents' understanding of how risks in their district relate to specific meteorological information, as well as promote the development of the very meteorological information necessary for improving future disaster response. We showed that improvements in meteorological information can support the establishment of a local "disaster response switch" by evaluating community-specific disaster risks, and that the role of meteorological information will be more important than ever when considering disaster response support in local communities.

Various forms of diversity are also seen in local communities. We must consider disaster response switches that can express the unique characteristics of each district so that they can function effectively in their respective districts. The issue is what meteorological information should be provided for residents to more easily and intuitively understand the relationship between the information and their local disaster risks. In addition to conventional improvements in meteorological information, further development of this concept will be necessary in future research.

Open Access This article is licensed under a Creative Commons Attribution 4.0 International License, which permits use, sharing, adaptation, distribution and reproduction in any medium or format, as long as you give appropriate credit to the original author(s) and the source, provide a link to the Creative Commons licence, and indicate if changes were made. The images or other third party material in this article are included in the article's Creative Commons licence, unless indicated otherwise in a credit line to the material. If material is not included in the article's Creative Commons licence and your intended use is not permitted by statutory regulation or exceeds the permitted use, you will need to obtain permission directly from the copyright holder. To view a copy of this licence, visit http://creativecommons. org/licenses/by/4.0/.

\section{References}

Alcántara-Ayala, I., and A.R. Moreno. 2016. Landslide risk perception and communication for disaster risk management in mountain areas of developing countries: A Mexican foretaste. Journal of Mountain Science 13(12): 2079-2093.

Asakura, Y., M. Hangyo, and M. Komachi. 2016. Disaster analysis using user-generated weather report. In Proceedings of the 2 nd Workshop on Noisy User-generated Text, 11-16 December 2016, Osaka, Japan, 24-32.

Aulov, O., and M. Halem. 2012. Human sensor networks for improved modeling of natural disasters. Proceedings of the IEEE 100(10): 2812-2823.

Buckland, J., and M. Rahman. 1999. Community-based disaster management during the 1997 Red River flood in Canada. Disasters 23(2): 174-191.

Cabinet Office. 2005. Cases of countermeasures against heavy rainfall and storm using community cooperation. http://www.bousai.go. jp/fusuigai/sonota/index.html. Accessed 29 Mar 2019 (in Japanese). 
Castro, C., J. Sarmiento, R. Edwards, G. Hoberman, and K. Wyndham. 2017. Disaster risk perception in urban contexts and for people with disabilities: Case study on the city of Iquique (Chile). Natural Hazards 86(1): 411-436.

Chen, L., Y. Liu, and K. Chan. 2006. Integrated community-based disaster management program in Taiwan: A case study of ShangAn village. Natural Hazards 37(1-2): 209-223.

Chou, J., and J. Wu. 2014. Success factors of enhanced disaster resilience in urban community. Natural Hazards 74(2): 661-686.

Dudhia, J. 2014. A history of mesoscale model development. AsiaPacific Journal of Atmospheric Sciences 50(1): 121-131.

Engel, K., G. Frerks, L. Velotti, J. Warner, and B. Weijs. 2014. Flood disaster subcultures in The Netherlands: The parishes of Borgharen and Itteren. Natural Hazards 73(2): 859-882.

Fang, S., L. Xu, Y. Zhu, and Y. Liu. 2015. An integrated information system for snowmelt flood early-warning based on internet of things. Information Systems Frontiers 17(2): 321-335.

Fukunaga, H., M. Masaki, and K. Kono. 2014. The first "emergency warning" issued for heavy rain caused by typhoon: How emergency information was delivered. The NHK Monthly Report on Broadcast Research 64(1): 2-29 (in Japanese).

GDPFS (Global Data-processing and Forecasting System). 2015. 2015 GDPFS/NWP reports. WMO technical progress report on the global data-processing and forecasting system and numerical weather prediction research. http://www.wmo.int/pages/prog/ www/DPFS/ProgressReports/2015/GDPFS-NWP-2015.html. Accessed 29 Mar 2019.

Geospatial Information Authority of Japan. 2014. FY2014 area survey of prefectures and municipalities in Japan. Tsukuba, Japan: Geospatial Information Authority of Japan (in Japanese).

Geospatial Information Authority of Japan. 2018. GSI tiles (seamless photo maps) with zoom level 12. https://cyberjapandata.gsi.go. jp/xyz/seamlessphoto/ $\{z\} /\{x\} /\{y\} . j p g$. Accessed 29 Mar 2019 (in Japanese).

Gierlach, E., B.E. Belsher, and L.E. Beutler. 2010. Cross-cultural differences in risk perceptions of disasters. Risk Analysis 30(10): $1539-1549$.

Gojmerac, I., A. Preinerstorfer, C. Ruggenthaler, C. Schuster, A. Almer, R. Stocker, and V. Heussler. 2016. Public warning and alert system for Austria. In Proceedings of the 2016 3rd International Conference on Information and Communication Technologies for Disaster Management, 13-15 December 2016, Vienna, Austria, 1-7.

Ho, M., D. Shaw, S. Lin, and Y. Chiu. 2008. How do disaster characteristics influence risk perception? Risk Analysis 28(3): 635-643.

IPCC (Intergovernmental Panel on Climate Change). 2012. Managing the risks of extreme events and disasters to advance climate change adaptation. A special report of working groups I and II of the Intergovernmental Panel on Climate Change, ed. CB. Field, V. Barros, T.F. Stocker, D. Qin, D.J. Dokken, K.L. Ebi, M.D. Mastrandrea, K.J. Mach, et al. Cambridge and New York: Cambridge University Press.

Isouchi, C. 2018. The heavy rainfall in west Japan in 2018 and community disaster prevention power-Case of Takahama district in Matsuyama, Ehime. Presented at the 2018 symposium of "The heavy rainfall in west Japan in 2018, community disaster prevention power and disaster recovery support", jointly hosted by the Japan Society of Community Disaster Management Plan and the College of Risk Management at Nihon University (in Japanese).

Japan Meteorological Agency. 2017. Joint WMO technical progress report on the global data processing and forecasting system and numerical weather prediction research activities for 2017. http:// www.jma.go.jp/jma/jma-eng/jma-center/nwp/report/2017_ Japan.pdf. Accessed 29 Mar 2019.
Japan Meteorological Agency. 2018a. The brochure of the Japan Meteorological Agency. https://www.jma.go.jp/jma/en/Activ ities/brochure201803.pdf. Accessed 29 Mar 2019 (in Japanese).

Japan Meteorological Agency. 2018b. Survey report on the utility of meteorological information. http://www.jma.go.jp/jma/kishou/ hyouka/manzokudo/29manzokudo/29manzokudo_data.pdf. Accessed 29 Mar 2019 (in Japanese).

Japan Meteorological Agency. 2018c. Meteorological reports on disasters: The heavy rainfall in northern Kyushu in July, 2017 and the continued rainfall from stationary seasonal rain front from 7 June to 27 July in 2017. http://www.jma.go.jp/jma/ kishou/books/saigaiji/saigaiji_2017/saigaiji_201801.pdf. Accessed 29 Mar 2019 (in Japanese).

Japan Meteorological Agency. 2019. Meteorological reports on disasters: The heavy rainfall in July 2018 and the continued rainfall from stationary seasonal rain front from 20 May to 10 July in 2018. http://www.jma.go.jp/jma/kishou/books/saigaiji/ saigaiji_2018/saigaiji_201902.pdf. Accessed 29 Mar 2019 (in Japanese).

Japan Meteorological Agency. 2020. 60 year history of numerical weather prediction. https://www.jma.go.jp/jma/kishou/know/ whitep/doc_1-3-2-1/all.pdf. Accessed 29 Mar 2019 (in Japanese)

Kakimoto, R., and T. Fujimi. 2013. Questionnaire survey of residents in the disaster area. Journal of Natural Disaster Science 32(1): 37-42 (in Japanese).

Katada, T., and M. Kanai. 2010. Design of communication to establish independent evaluation rules for slope disasters by residents. Journal of the Japan Society of Civil Engineers F5-1(1): 106-121 (in Japanese).

Katada, T., Y. Oikawa, and M. Kodama. 2005. Study on the determination process of human behavior in flood disasters. Journal of the Japan Society of Civil Engineers 786/IV-67: 77-88 (in Japanese).

Katada, T., Y. Oikawa, and Y. Shimizu. 1998. A study on the decision making process of the evacuation activities during a flood. Advances in River Engineering 4(1): 291-296 (in Japanese).

Kayano, T. 2001. Cyclone shelters and Mizuya: Toward a third culture of disaster management. Hokusei Review of the School of Economics at Hokusei Gakuen University 39: 39-52 (in Japanese).

Kurokawa, M., and H. Seiwa. 1986. Effects of residents' place identity on their anxiety about a flood and coping strategies. The Japanese Journal of Psychology 57(2): 91-94 (in Japanese).

Kaziya, A., K. Akaishi, T. Yokota, F. Kusano, N. Sekiya, and Y. Takahashi. 2018. Reduction of evacuation rate after the Izu Oshima sediment disaster in 2013 and examination of its cause and measures based on a questionnaire survey. Disaster Information 16(1): 37-47 (in Japanese).

Kobayashi H., and A. Tanaka. 2017. Effect of disaster knowledge structure on residents' behavioral intention against disaster Case of Kanto Tohoku heavy rainfall disaster 2015. Disaster Information 15(2): 137-147 (in Japanese).

Kodama, M., M. Kanai, T. Katada, and M. Hatano. 2014. Study on evacuation characteristics based on a survey of residents' decision-making with a disaster scenario role-playing system. Disaster Information 12(1): 64-75 (in Japanese).

Kusano F., T. Yokota, K. Akaishi, I. Matsuo, and A. Nimoto. 2015. Survey of evacuation intentions during a heavy rainfall disaster in Kiho, Mie prefecture. Disaster Information 13(1): 96-100 (in Japanese).

McLennan, B.J. 2018. Conditions for effective coproduction in community-led disaster risk management. VOLUNTAS: International Journal of Voluntary and Nonprofit Organizations 31(2): 316-332. 
Ministry of Education, Culture, Sports, Science and Technology. 2015. FY2015 school basic survey. Tokyo: Ministry of Education, Culture, Sports, Science and Technology (in Japanese).

Ministry of Internal Affairs and Communications. 2013. FY2013 survey of administrative affairs on community associations. Tokyo: Ministry of Internal Affairs and Communications (in Japanese).

Ministry of Land, Infrastructure, Transport and Tourism. 2018. Summary of river project 2018. http://www.mlit.go.jp/river/ pamphlet_jirei/kasen/gaiyou/panf/pdf/c1.pdf. Accessed 29 Mar 2019 (in Japanese).

NHK (Japan Broadcasting Corporation). 2018. Morning close-up (Kesa no kurōzuappu), broadcast on 1 August 2018. https:// www.nhk.or.jp/ohayou/digest/2018/08/0801.html. Accessed 29 Mar 2019 (in Japanese).

Oikawa, Y., N. Kodama, and T. Katada. 2005. Study on the determination process of human behavior in flood disasters. Journal of the Japan Society of Civil Engineers 786/IV-67: 89-101 (in Japanese).

Oikawa, Y., and T. Katada. 2016. Effects of a repetitive false evacuation advisory on residents' behavior. Disaster Information 14(1): 93-104 (in Japanese).

Pearce, L. 2003. Disaster management and community planning, and public participation: How to achieve sustainable hazard mitigation. Natural Hazards 28(2): 211-228.

Qadir, J., A. Ali, R. Rasool, A. Zwitter, A. Sathiaseelan, and J. Crowcroft. 2016. Crisis analytics: Big data-driven crisis response. Journal of International Humanitarian Action 1(1): $1-21$.

Saito, K., J. Ishida, K. Aranami, T. Hara, T. Segawa, M. Narita, and Y. Honda. 2007. Nonhydrostatic atmospheric models and operational development at JMA. Journal of the Meteorological Society of Japan 85B: 271-304.

Sayo-cho Tropical Storm Etau Disaster Investigation Committee. 2010. Investigation report of the tropical storm Etau disaster in 2009. Sayo, Japan: Sayo-cho Tropical Storm Etau Disaster Investigation Committee (in Japanese).

Siebeneck, L.K., and T.J. Cova. 2012. Spatial and temporal variation in evacuee risk perception throughout the evacuation and returnentry process. Risk Analysis 32(9): 1468-1480.

$\mathrm{Su}, \mathrm{Y}$., F. Zhao, and L. Tan. 2015. Whether a large disaster could change public concern and risk perception: A case study of the $7 / 21$ extraordinary rainstorm disaster in Beijing in 2012. Natural Hazards 78(1): 555-567.

Takahagi, K., T. Ishida, A. Sakuraba, K. Sugita, N. Uchida, and Y. Shibata. 2015. Proposal of the disaster information transmission common infrastructure system intended to rapid sharing of information in a time of mega disaster. In Proceedings of the 18th International Conference on Network-Based Information Systems, 2-4 September 2015, Taipei, China, 505-510.

Takahashi, K. 2014. Disaster mitigation lore "distribution of manjū (bean cakes). In Disaster mitigation lores-Community wisdoms to save lives, ed. K. Takahashi, 83-110. Tokyo: Kokonshoin Press (in Japanese).

Takenouchi, K., C. Nakanishi, K. Yamori, M. Sawada, K. Takeuchi, and H. Fujiwara. 2015. A trial of collaboration on local weather information at Nakajima school district in Ise. Journal of Natural Disaster Science 34(3): 243-258 (in Japanese).

Takenouchi, K., Y. Kano, and K. Yamori. 2018. Role of community judgment standards in northern Kyushu heavy rainfall in 2017Function of disaster response switch during disasters. Journal of the Japan Society of Civil Engineers F6-74(2): I_31-I_39 (in Japanese).

Tanaka, K., K. Umeno, M. Ikeda, and M. Hori. 2015. Psychological investigation on the perceived danger of unsafe evacuation behavior in knowledge-to-action gap. Cognitive Studies 22(3): 356-367 (in Japanese).

Usuda, Y., M. Hanashima, R. Sato, and H. Sano. 2017. Effects and issues of information sharing system for disaster response. Journal of Disaster Research 12(5): 1002-1014.

Ushiyama, M. 2014. An analysis of residents' understanding of heavy rainfall emergency warnings in a flood inundation area. Special Issue of Journal of Natural Disaster Science 33(1): 75-85 (in Japanese).

Wei, J., F. Wang, and M.K. Lindell. 2016. The evolution of stakeholders' perceptions of disaster: A model of information flow. Journal of the Association for Information Science and Technology 67(2): 441-453.

Working group on evacuations from water-related disasters, landslides, and debris flows caused by the heavy rainfall in July 2018. 2018. Issues and realities of the heavy rainfall in July 2018. The third reference document in "Report on evacuations from water-related disasters, landslides, and debris flows caused by the heavy rainfall in July $2018^{\prime \prime}$. http://www.bousai.go.jp/ fusuigai/suigai_dosyaworking/pdf/sankosiryo3.pdf. Accessed 29 Mar 2019 (in Japanese).

Xiao, Y., Q. Huang, and K. Wu. 2015. Understanding social media data for disaster management. Natural Hazards 79(3): $1663-1679$.

Yamori, K. 2009. The double bind of disaster information. Disaster Information 7(1): 28-33 (in Japanese).

Yasumoto, S., M. Ushiyama, and N. Sekiya. 2018. Analysis on evacuation behavior during the typhoon No.1610 disaster in Iwaizumi town. Journal of Natural Disaster Science 37(1): 33-45 (in Japanese).

Zhang, X., L. Yi, and D. Zhao. 2013. Community-based disaster management: A review of progress in China. Natural Hazards 65(3): 2215-2239.

Zhu, R., Y. Liu, H. Jiang, and Z. Yin. 2011. Visualization of weatherinduced disaster warning information system using Google Earth API based on Mashup. In Proceedings of the 2011 International Conference on Multimedia Technology, 26-28 July 2011, Hangzhou, China, 3789-3793. 